\title{
EFEITO DA TEMPERATURA DE GASEIFICAÇÃO DE BIOMASSA NA ADSORÇÃO DE CORANTE REATIVO
}

\author{
J. J. SORNAS ${ }^{1}$, W. UTECH JUNIOR ${ }^{1}$, R. F. dos SANTOS ${ }^{1}$, A. R. VASQUES ${ }^{2}$, C. \\ MARANGON ${ }^{1}$ I, C. R. L. de AGUIAR ${ }^{1}$, E. FONTANA ${ }^{1}$, R. C. S. C. VALLE ${ }^{1}$, J. A. B. \\ VALLE ${ }^{1}$, \\ ${ }^{1}$ Universidade Federal de Santa Catarina, Campus Blumenau, Curso de Engenharia Têxtil \\ ${ }^{2}$ Universidade de Brasília, Instituto de química \\ E-mail para contato: jessica.sornas@grad.ufsc.br
}

\begin{abstract}
RESUMO - O grande desafio atual das indústrias têxteis é a devolução da água aos rios dentro dos parâmetros exigidos pela legislação. Neste trabalho é apresentada uma perspectiva sustentável para utilização do lodo residual gerado pelas estações de tratamento de efluente, com a finalidade de proporcionar a remoção de corante do efluente. Especificamente estudou-se o efeito da temperatura de gaseificação de lodo seco para produção de adsorventes. Foram realizados ensaios de adsorção com o lodo gaseificado para remoção dos corantes preto remazol $\mathrm{N}$ gran $150 \%$ e reativo vermelho RGB. A temperatura de gaseificação de $550{ }^{\circ} \mathrm{C}$ foi a que produziu um adsorvente com maior capacidade de remoção de corante.
\end{abstract}

\section{INTRODUÇÃO}

Os corantes reativos são um dos mais utilizados pelas indústrias têxteis e segundo Vasques (2008) os que possuem grupo cromóforo azo (azocorantes) representam cerca de $60 \%$ dos utilizados no mundo. Dessa forma o estudo da adsorção desse tipo de corante se torna essencial.

"Estima-se que de 1\% a 15\% dos corantes utilizados pelas indústrias têxteis são perdidos durante o processo de tingimento e liberados no efluente" (VASQUES, 2008 P. 18). Para os corantes reativos estima-se que a perda é ainda maior, cerca de 30-50\%. Ainda há dificuldade para remoção da cor do efluente, pois geralmente os processos atuais possuem custo elevado, contudo, é necessário realizar pesquisa para uma alternativa eficiente, sustentável e com menores custos. Um efluente colorido que é despejado em rios é facilmente identificado por órgãos ambientais e até mesmo pela sociedade, trazendo grandes consequências para a indústria.

O lodo gerado pelo tratamento de efluentes é um grande problema no cotidiano das indústrias. Ele é produzido em grande quantidade e a disposição final frequente é o aterro industrial. Essa disposição é inadequada devido a grande carga de metais pesados presentes no lodo. Além disso, essa disposição final gera custos com secagem do lodo (para diminuição do volume do resíduo), com transporte e com o aterro. 


\section{Congresso Brasileiro de Engenharia Química em Iniciação Científica Unicamp - Campinas - SP 19 a 22 de julho de 2015}

A pirólise é um processo de tratamento térmico em que o lodo é volatizado sob-baixa pressão na temperatura de $350-500{ }^{\circ} \mathrm{C}$ na ausência completa de oxigênio. Com a pirólise da biomassa (lodo) há conversão em carvão (adsorvente), óleos de pirólise, vapor d'água e gases combustíveis (VASQUES, 2012). "A gaseificação é um tipo de pirólise, realizado a altas temperaturas e longo tempo de residência da biomassa e visa otimizar a produção de gás" (FERNANDES, 2012 apud ASSUMPÇÃO, 1981).

Neste trabalho foi realizada a gaseificação em presença de oxigênio da biomassa com o objetivo de gerar carvão ativado para adsorção de corantes reativos. Analisou-se a capacidade de adsorção do carvão ativado quando gaseificado em duas temperaturas diferentes.

\section{METODOLOGIA}

\subsection{Gaseificação}

Para os ensaios de adsorção foram utilizados dois adsorventes. Ambos foram feitos a partir de lodo seco da estação de tratamento de efluentes de uma indústria têxtil da cidade de Blumenau. Os ensaios de gaseificação do lodo seco foram realizados em mufla na presença de oxigênio. O lodo seco peneirado em malha de 100 mech foi colocado em quatro cadinhos que foram inseridos na mufla e gaseificado a $550{ }^{\circ} \mathrm{C}$ por uma hora. Dois dos quatro cadinhos foram retirados e colocados em dessecador até resfriarem a temperatura ambiente e dois permaneceram na mufla por mais uma hora a $700{ }^{\circ} \mathrm{C}$.

\subsection{Corantes e Correção de pH}

Os corantes utilizados foram o preto Remazol N gran 150\% da Dystar e o reativo RGB vermelho. Foi preparada uma solução de cada corante com concentração de $100 \mathrm{mg} / \mathrm{L}$ (solução mãe), onde $100 \mathrm{mg}$ de cada corante foi pesada com o auxílio da balança analítica Metler Toledo modelo AB204-s, e para melhor solubilidade dos corantes eles foram dissolvidos inicialmente em $10 \mathrm{~mL}$ de água quente e depois em $990 \mathrm{~mL}$ de água a temperatura ambiente.

Em doze frascos erlenmeyers foram colocados $95 \mathrm{~mL}$ de água destilada e com o uso do medidor de $\mathrm{pH}$ da Marca Quimis, modelo 400M2, foi corrigido o $\mathrm{pH}$ de cada um dos frascos para $\mathrm{pH} 5,7$ e 9 .

Após a correção do $\mathrm{pH}$ foram adicionados $5 \mathrm{~mL}$ da solução mãe de corante nos erlenmeyers obtendo-se uma solução com concentração de $5 \mathrm{mg}$ de corante/L. Em cada erlenmeyer foi colocado $0,5 \mathrm{~g}$ de adsorvente (5 $\mathrm{g}$ adsorvente/L). Assim que o adsorvente foi adicionado a solução de corante (tempo $0 \mathrm{~h}$ ), os erlenmeyers foram colocados no agitador da marca Tholz e modelo MDH em 116 RPM.

\subsection{Curva de Calibração}

Para a construção da curva de calibração, partiu-se da solução de corantes com concentração de $100 \mathrm{mg} / \mathrm{L}$ e foram feitas soluções de $10,5,3,2,5$ e $1 \mathrm{mg} / \mathrm{L}$ e essas soluções foram analisadas no espectrofotômetro da marca Shimadzu, modelo UV-mini 1240. As 


\section{Congresso Brasileiro de Engenharia \\ Química em Iniciação Científica Unicamp - Campinas - SP 19 a 22 de julho de 2015}

análises do corante vermelho foram realizadas no comprimento de onda de $517 \mathrm{~nm}$ e do corante preto no de $598 \mathrm{~nm}$. Foram usados esses pontos de concentração, pois para analisar a adsorção busca-se uma curva de calibração com concentrações próximas da concentração inicial e final dos ensaios de adsorção.

\subsection{Planejamento Experimental}

Na Tabela 1 são apresentadas as condições experimentais dos ensaios realizados. Essas condições experimentais foram utilizadas para ambos os corantes.

Tabela 1 - Planejamento experimental corante vermelho e preto.

\begin{tabular}{cc}
\hline Adsorvente & $\mathrm{pH}$ \\
\hline Lodo gaseificado $550^{\circ} \mathrm{C}$ & 5 \\
Lodo gaseificado $550^{\circ} \mathrm{C}$ & 7 \\
Lodo gaseificado $550^{\circ} \mathrm{C}$ & 9 \\
Lodo gaseificado $700^{\circ} \mathrm{C}$ & 5 \\
Lodo gaseificado $700^{\circ} \mathrm{C}$ & 7 \\
Lodo gaseificado $700^{\circ} \mathrm{C}$ & 9 \\
\hline
\end{tabular}

\subsection{Cinética de Adsorção}

O adsorvente utilizado para obter-se a cinética de adsorção foi o lodo seco gaseificado em Mufla a $550{ }^{\circ} \mathrm{C}$ durante uma hora. Os corantes utilizados foram o preto Remazol $\mathrm{N}$ gran $150 \%$ da Dystar e o corante reativo RGB vermelho.

Em seis erlenmeyers foi adicionado $190 \mathrm{~mL}$ de água destilada e então foi realizada a correção do $\mathrm{pH}$ para $\mathrm{pH} \mathrm{5,7} \mathrm{e} \mathrm{9.} \mathrm{Após} \mathrm{a} \mathrm{correção} \mathrm{do} \mathrm{pH}$, adicionou-se $10 \mathrm{~mL}$ da solução mãe de corantes em cada frasco, obtendo-se a concentração de $5 \mathrm{mg}$ de corante/L. O planejamento experimental da cinética de adsorção é apresentado na Tabela 2.

Tabela 2 - Planejamento experimental cinética de adsorção

\begin{tabular}{cccc}
\hline $\begin{array}{c}\text { Identificação do } \\
\text { erlenmeyer }\end{array}$ & Corante & Adsorvente & $\mathrm{pH}$ \\
\hline R5 & Vermelho RGB & & 5 \\
R7 & Vermelho RGB & Lodo gaseificado $550^{\circ} \mathrm{C}$ & 9 \\
R9 & Vermelho RGB & & 5 \\
B5 & Preto Remazol & 7 \\
B7 & Preto Remazol & 9 \\
B9 & Preto Remazol & \\
\hline
\end{tabular}

Utilizou-se $1 \mathrm{~g}$ de adsorvente (5g de adsorvente/L) e assim que o adsorvente foi adicionado, retirou-se uma amostra para análise em espectrofotômetro. Os ensaios tiveram 


\section{Congresso Brasileiro de Engenharia Química em Iniciação Científica Unicamp - Campinas - SP 19 a 22 de julho de 2015}

duração de $2 \mathrm{~h}$ e foram retiradas várias amostras para análise em espectrofotômetro durante os mesmos.

\section{RESULTADOS}

\subsection{Curva de Calibração}

As medidas de absorvância foram feitas para ter uma curva de calibração, onde é possível determinar a concentração final de corante após a adsorção. A partir dos dados obtidos com o espectrofotômetro construiu-se os gráficos dos dois corantes que são apresentados nas Figura 1.

Figura 1 - Curva de calibração corante vermelho RGB e preto remazol.

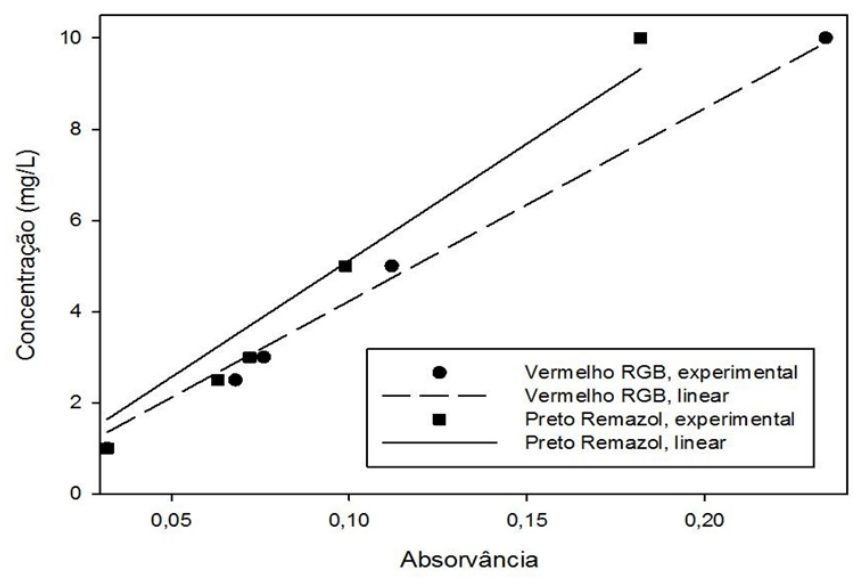

Através dos dados medidos foi realizado o ajuste de mínimos quadrados de forma que é possível expressar o comportamento da concentração de corante (c) em função da absorvância (abs) pela equação $1 \quad(c(a b s)=42,300 a b s)$ para o corante vermelho $\mathrm{e}$ a equação 2 ( $c(a b s)=51,231 a b s)$ para o corante preto. $\mathrm{O}$ coeficiente de correlação do corante preto remazol foi $\mathrm{R}^{2}=0,986$ e para o vermelho $\mathrm{RGB}$ o $\mathrm{R}^{2}=0,997$.

\subsection{Ensaios de Adsorção}

Após dezenove horas de agitação foram retirados os erlenmeyers e foi realizado a medida da absorvância de cada um deles. A partir das equações 1 e 2 foi possível calcular a concentração de corante após a adsorção com a absorvância medida. Na Tabela 3 são apresentados os resultados de concentração para o corante vermelho e para o corante preto.

\subsection{Influência do pH nos Ensaios de Adsorção}

Analisando a Tabela 3 é possível identificar que a melhor combinação para o corante vermelho foi no $\mathrm{pH} 7$ com o lodo gaseificado a $550^{\circ} \mathrm{C}$ e para o corante preto também foi em pH 7 com o lodo gaseificado a $550^{\circ} \mathrm{C}$, pois são os que apresentam menor percentual de corante remanescente na solução. 


\section{Congresso Brasileiro de Engenharia \\ Química em Iniciação Científica Unicamp - Campinas - SP 19 a 22 de julho de 2015}

A concentração inicial foi de $5 \mathrm{mg} / \mathrm{L}$ de ambos corantes, dessa forma foi visto que o lodo gaseificado a $700^{\circ} \mathrm{C}$ teve um pior índice de adsorção para ambos os corantes, pois como consta na Tabela 4 as concentrações finais ficaram entre 0,922 - 1,946 mg/L. adsorção.

Tabela 3 - Concentração e percentual de corante na solução remanescente após

\begin{tabular}{cccccc}
\hline $\begin{array}{c}\text { Identificação } \\
\text { do } \\
\text { erlenmeyer }\end{array}$ & Corante & Adsorvente & $\mathrm{pH}$ & $\begin{array}{c}\text { Concentração } \\
\text { após adsorção } \\
(\mathrm{mg} / \mathrm{L})\end{array}$ & $\begin{array}{c}\% \text { de } \\
\text { corante na } \\
\text { solução }\end{array}$ \\
\hline $\mathrm{C}_{2} 5-\mathrm{P}$ & Preto Remazol & Lodo gaseificado $550{ }^{\circ} \mathrm{C}$ & 5 & 0,819 & 16,3 \\
$\mathrm{C}_{2} 7-\mathrm{P}$ & Preto Remazol & Lodo gaseificado $550{ }^{\circ} \mathrm{C}$ & 7 & 0,512 & 10,2 \\
$\mathrm{C}_{2} 9-\mathrm{P}$ & Preto Remazol & Lodo gaseificado $550{ }^{\circ} \mathrm{C}$ & 9 & 1,075 & 21,5 \\
$\mathrm{C}_{3} 5-\mathrm{P}$ & Preto Remazol & Lodo gaseificado $700^{\circ} \mathrm{C}$ & 5 & 0,922 & 18,4 \\
$\mathrm{C}_{3} 7-\mathrm{P}$ & Preto Remazol & Lodo gaseificado $700^{\circ} \mathrm{C}$ & 7 & 1,946 & 38,9 \\
$\mathrm{C}_{3} 9-\mathrm{P}$ & Preto Remazol & Lodo gaseificado $700{ }^{\circ} \mathrm{C}$ & 9 & 1,229 & 24,5 \\
$\mathrm{C}_{2} 5-\mathrm{V}$ & Vermelho RGB & Lodo gaseificado $550{ }^{\circ} \mathrm{C}$ & 5 & 0,972 & 19,4 \\
$\mathrm{C}_{2} 7-\mathrm{V}$ & Vermelho RGB & Lodo gaseificado $550{ }^{\circ} \mathrm{C}$ & 7 & 0,423 & 8,46 \\
$\mathrm{C}_{2} 9-\mathrm{V}$ & Vermelho RGB & Lodo gaseificado $550^{\circ} \mathrm{C}$ & 9 & 0,930 & 18,6 \\
$\mathrm{C}_{4} 5-\mathrm{V}$ & Vermelho RGB & Lodo gaseificado $700^{\circ} \mathrm{C}$ & 5 & 1,607 & 32,1 \\
$\mathrm{C}_{4} 7-\mathrm{V}$ & Vermelho RGB & Lodo gaseificado $700^{\circ} \mathrm{C}$ & 7 & 1,522 & 30,4 \\
$\mathrm{C}_{4} 9-\mathrm{V}$ & Vermelho RGB & Lodo gaseificado $700{ }^{\circ} \mathrm{C}$ & 9 & 1,311 & 26,2 \\
\hline
\end{tabular}

\subsection{Influência da Temperatura de Gaseificação nos Ensaios de Adsorção}

Entre os dois lodos utilizados o melhor adsorvente foi o gaseificado a $550^{\circ} \mathrm{C}$, pois conseguiu remover mais corante que o gaseificado a $700^{\circ} \mathrm{C}$. A partir da análise visual da biomassa gaseificada a $700^{\circ} \mathrm{C}$ identificou-se a formação de cinzas na superfície, assim considerou-se que nas condições que foi gaseificado não obteu-se um bom adsorvente. O lodo gaseificado a $700^{\circ} \mathrm{C}$ é apresentado na Figura 2.

Figura 2 - Lodo após gaseificação a $700^{\circ} \mathrm{C}$.

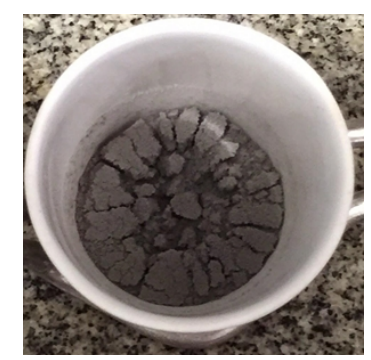

\subsection{Cinética de Adsorção}

Para o corante preto remazol foi utilizado o ajuste de pseudo segunda ordem, onde o $\mathrm{qe}=0,5390 \pm 0,0347[\mathrm{mg} / \mathrm{g}]$ e a constante $\mathrm{k}=0,0928 \pm 0,0253$, foi utilizado esse ajuste pois obteve- 


\section{Congresso Brasileiro de Engenharia \\ Química em Iniciação Científica Unicamp - Campinas - SP 19 a 22 de julho de 2015}

se o coeficiente de correlação maior que o de pseudo primeira ordem, o valor de $\mathrm{R}^{2}=0,9775$ para a cinética de pseudo segunda ordem. Na cinética do corante vermelho RGB utilizou-se o ajuste de pseudo primeira ordem, onde o $\mathrm{qe}=0,4567 \pm 0,0347$ e a constante $\mathrm{k}=0,0216 \pm 0,0038$ e o coeficiente de correlação corresponde a 0,9804 .

A partir da Figura 3 é possível analisar que a quantidade dos corantes no adsorvente (q) aumentou com o passar do tempo como era esperado. Com os dados experimentais obtidos não foi possível atingir o equilíbrio do sistema.

Figura 3 - Cinética de adsorção dos corantes Preto Remazol e Vermelho RGB em pH 7

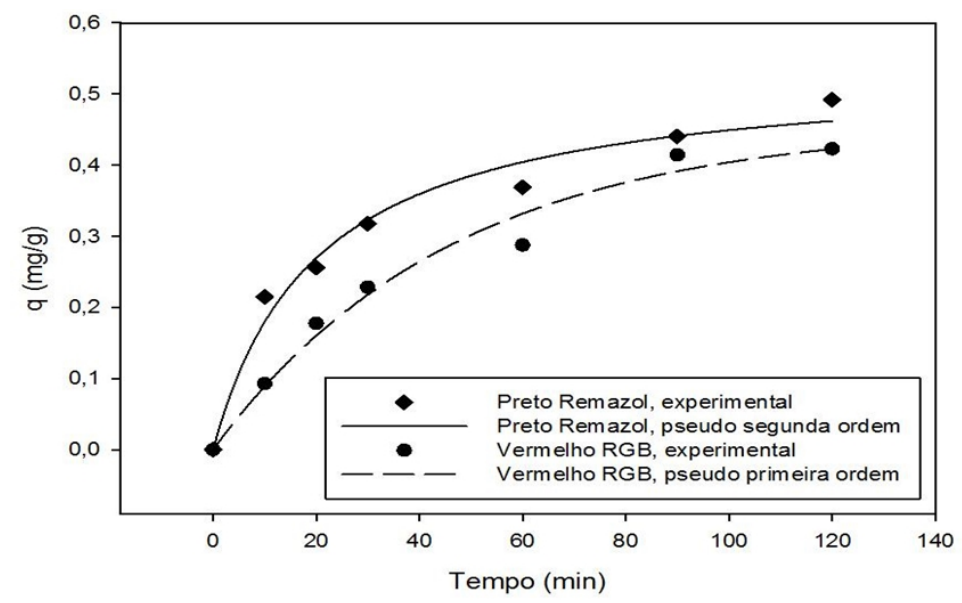

\section{CONSIDERAÇÕES FINAIS}

A partir dos resultados obtidos observou-se que o aumento da temperatura de gaseificação diminuiu a capacidade de adsorção da biomassa gaseificada. O lodo gaseificado a $550^{\circ} \mathrm{C}$ foi eficaz para a remoção dos dois tipos de corantes estudados, onde o percentual máximo de remoção de cor foi de $91,54 \%$ para ensaio com o corante vermelho RGB e em pH 7. Para os próximos trabalhos pode-se ativar quimicamente o lodo após a gaseificação com o intuito de melhorá-lo como adsorvente.

\section{REFERÊNCIAS}

FERNANDES, E. R. K. Valorização de resíduos gerados na bananicultura por pirólise. 2012. 88 f. Dissertação (Mestrado em Engenharia de Processos) - Universidade da Região de Joinville, Joinville.

VASQUES, A. R. Caracterização e aplicação de adsorvente para remoção de corantes de efluentes têxteis em batelada e colunas de leito fixo. 2008. 153 f. Dissertação (Mestrado em Engenharia Química) - Universidade Federal de Santa Catarina, Florianópolis.

VASQUES, A. R. Caracterização de adsorventes obtidos por combustão e pirólise de lodo residual e aplicação no tratamento de efluentes têxteis. 2012. $130 \mathrm{f}$. Tese (Doutorado em Engenharia Química) - Universidade Federal de Santa Catarina, Florianópolis. 